\title{
Homocysteine and coronary heart disease in the Caerphilly cohort: a 10 year follow up
}

\author{
U B Fallon, Y Ben-Shlomo, P Elwood, J B Ubbink, G Davey Smith
}

\begin{abstract}
Objective-Prospective assessment of the risk of coronary heart disease associated with total serum homocyst(e)ine (homocysteine) concentration.

Design-Nested case-control study.

Setting-Caerphilly and surrounding villages in south Wales, UK.

Participants-2290 men who participated in phase II of the study in 1984. After a mean follow up of 10 years, 312 men developed coronary heart disease and were compared with 1248 randomly selected, age frequency matched controls.

Main outcome measure-Acute myocardial infarction or death from coronary heart disease. Results-The geometric mean serum homocysteine concentration was higher in cases $(12.2 \mu \mathrm{mol} / 1,95 \%$ confidence interval (CI) 11.8 to $12.6 \mu \mathrm{mol} / \mathrm{l})$ than in controls $(11.8 \mu \mathrm{mol} / 1$, $95 \%$ CI 11.3 to $12.5 \mu \mathrm{mol} / 1)(\mathrm{p}=0.09)$. There was a graded increase in the odds ratio of coronary heart disease across quintiles of the homocysteine concentration distribution compared with the first $(p=0.04)$, which was attenuated when adjusted for confounding variables $(p=0.4)$. There was a small but non-significant increase in the adjusted odds ratio of coronary heart disease per standard deviation change in the log distribution of homocysteine concentration $(\mathrm{OR}=1.07(95 \% \mathrm{CI} .93$ to 1.24$), \mathrm{p}=0.34)$. Comparing the top quintile of the homocysteine concentration with the remaining $80 \%$, the adjusted odds ratio of coronary heart disease was 1.03 $(95 \%$ CI 0.73 to 1.45$)(\mathrm{p}=0.8)$ and comparing the top 5\% with the remaining $95 \%$ it was 1.05 $(95 \%$ CI 0.56 to 1.95$)(\mathrm{p}=0.9)$.

Conclusions-These findings do not support the hypothesis that a raised homocysteine concentration is a strong independent risk factor for coronary heart disease. Randomised controlled trials of homocysteine lowering treatment such as folic acid are needed before generalising the early positive results of observational studies.
\end{abstract}

(Heart 2001;85:153-158)

Keywords: homocysteine; coronary heart disease; cohort

Department of Social Medicine, University of Bristol, Canynge Hall, Whiteladies Rd, Bristol BS8 2PR, UK U B Fallon Y Ben-Shlomo G Davey Smith

MRC Epidemiology Unit, Llandough Hospital, Penarth, South Glamorgan CF64 2XW, UK

P Elwood

University of Pretoria, Department of Chemical Pathology, Faculty of Medicine, PO Box 2034, Pretoria 0001, South Africa J B Ubbink

Correspondence to: Dr Fallon

una.fallon@bristol.ac.uk

Accepted 12 September 2000
Hyperhomocysteinaemia has been proposed as an independent risk factor for atherosclerotic vascular disease. ${ }^{1}$ This is an important hypothesis because blood homocysteine concentrations can be easily and cheaply reduced by taking folic acid. ${ }^{2}$ Although there is no proof of causality, the homocysteine cardiovascular disease hypothesis is biologically plausible as homocysteine is known to be toxic to vascular endothelium at very high concentrations, and young adults with congenital hyperhomocysteinuria die prematurely of atherosclerosis and thrombosis. ${ }^{3}$

In recent years population based epidemiological studies have examined the influence of raised total serum homocyst(e)ine (homocysteine) concentration on atherosclerotic vascular disease, particularly coronary heart disease. The initial evidence suggesting that this is a strong independent risk factor for coronary heart disease came predominantly from cross sectional $^{4}$ and retrospective case-control studies. $^{5}$ A meta-analysis estimated an odds ratio of coronary heart disease of 1.6 (95\% confidence interval (CI) 1.4 to 1.7 ) for every $5 \mu \mathrm{mol}$ increase in plasma homocysteine. ${ }^{6}$

Since then more cohort studies and nested case-control studies have been published and the evidence has been more variable. Three prospective population based cohort studies of coronary heart disease and homocysteine con- centration, with a nested case-control design, showed a linear association between increasing homocysteine concentrations and coronary heart disease events..$^{7-9}$ The US physicians study showed a positive association in the top $5 \%$ of the homocysteine distribution in comparison with the bottom $90 \%$, suggesting a threshold effect. ${ }^{10}$ However, they failed to reproduce the effect when the subjects were followed for a longer period. ${ }^{11}$ Their study of stroke $^{12}$ and angina ${ }^{13}$ did not show an association.

A threshold effect has also been observed in two recent reports. The British regional heart study showed an increased risk of coronary heart disease when the top fifth of the homocysteine concentration distribution was compared with the rest (adjusted odds ratio $1.75,95 \%$ CI 1.2 to 2.55 ), but failed to show a significant association when the data were examined for linear effects; the adjusted odds ratio for 1 SD increase in the $\log$ of homocysteine concentration was 1.17 (95\% CI 0.99 to 1.38$), p=0.07 .{ }^{14}$ The Framingham study found an adjusted odds ratio of cardiovascular disease mortality of 1.52 (95\% CI 1.16 to 1.98 ) comparing the top quartile of the homocysteine concentration distribution with the rest. Two large US population based cohorts the atherosclerosis risk in the community study ${ }^{15}$ and MRFIT (multiple risk factor 
intervention trial $)^{16}$ failed to show an association, nor did a Finnish study. ${ }^{17}$

We have already reported the five year follow up of the relation between homocysteine concentration and coronary heart disease in the Caerphilly cohort. ${ }^{18}$ The odds ratio of a coronary heart disease event showed a significant trend with increasing quintiles, but this effect disappeared after adjusting for confounding variables. The adjusted mean difference of homocysteine concentration between cases $(12.2 \mu \mathrm{mol} / \mathrm{l})$ and non-cases $(11.7 \mu \mathrm{mol} /$ 1) was not significant. Lack of power and the possibility of a type II error may have been responsible for our null result. Given the current uncertainty about the importance of homocysteine, we now report the relation after 10 years of follow up and with twice as many cases.

\section{Methods}

DESIGN

The Caerphilly study is a prospective study of cardiovascular disease and related outcomes in men aged 45-59 years. They were identified from electoral rolls and were recruited between 1979 and 1983 from the town of Caerphilly, south Wales, and the adjacent villages. The men have been seen four times (phase I, II, III, and IV) over the past 20 years. Homocysteine concentration was measured on stored blood samples which were obtained from 2290 men who participated in phase II of the study in 1984. Follow up of coronary heart disease events is complete to the end of phase IV. In this paper we examine the relation between homocysteine concentration and coronary heart disease in men who had a coronary heart disease event over a mean follow up time of 10 years between phase II and IV (completed by the end of December 1997), plus those who died from coronary heart disease up to April 1998. A nested case-control design was used. Four controls ( $n=1248)$ were randomly selected for each case $(n=312)$, using age frequency matching within three age categories (50-54 years, 55-59 years, and 60-65 years).

MEASUREMENT OF EXPOSURES

In the phase II follow up the following measurements were collected: medical history, smoking history, London School of Hygiene and Tropical Medicine (LSHTM) chest pain questionnaire, height, weight, blood pressure measured with a random zero sphygmomanometer, and a 12 lead ECG. Detailed methods for these and the wide range of other measures-including cholesterol, triglycerides, and fibrinogen - were made and are described elsewhere. ${ }^{1920}$ Hypertension was defined as systolic blood pressure over $160 \mathrm{~mm} \mathrm{Hg}$, diastolic blood pressure over $95 \mathrm{~mm} \mathrm{Hg}$, or self reported hypertension on the questionnaire.

A detailed food frequency questionnaire was self completed before participants attended the clinic and was checked in the clinic by a dietician. These questionnaires were used to estimate the mean daily dietary intake of nutrients and vitamins. Participants were asked to return fasting within the next two weeks, when a blood sample was obtained. All subjects except 68 men $(4.4 \%)$ were fasting when the blood was taken.

\section{LABORATORY METHODS}

Serum was separated within a maximum of two hours of obtaining the sample and stored at below $-20^{\circ} \mathrm{C}$ for between $6-10$ years. Estimations of a wide range of factors relevant to cardiovascular disease were made and are described elsewhere. ${ }^{19}{ }^{20}$ Later, blood samples were transported on dry ice to South Africa for analysis of serum homocysteine concentration. A modification ${ }^{21}$ of the high performance liquid chromatography method described by Araki and Sako was performed in duplicate on every sample. The mean of the two measurements was used in the analysis. One hundred and twelve samples were split and placed blindly throughout the sample series. The coefficient of variation for these duplicate samples was $9 \%$ when one outlier was omitted.

Throughout, "homocysteine" refers to total serum homocyst(e)ine concentration, which is the sum of the concentrations of free homocysteine, protein bound homocysteine, the disulfide homocystine, and the mixed disulfide homocysteine-cysteine.

CORONARY HEART DISEASE ASCERTAINMENT

An attempt was made to identify every coronary heart disease event during the 10 year follow up. At phase III and IV, surviving men were invited to a clinic where the LSHTM questionnaire and the ECG were repeated. They were also asked about hospital admissions for chest pain. Men who moved out of the area were sent a self administered version of the chest pain questionnaire. Lists maintained for hospital activity analysis were used to identify men who were admitted to the local hospitals with myocardial infarction (International Classification of Diseases, ninth revision (ICD-9) 410-414). In addition, all men in the cohort have been flagged at the UK National Health Service central registry, and notification of deaths with certified cause is automatic.

Three types of major incident ischaemic heart disease events have been used as follows: (1) death from coronary heart disease where the death certificate is coded to ICD-9 410-414; (2) clinical myocardial infarction with hospital admission which fulfils the World Health Organization criteria; and (3) ECG myocardial infarction which fulfils the WHO categories, namely no Q-QS wave on recruitment (Minnesota codes 1-1, 1-2, or 1-3) and major or moderate Q-QS waves on follow up (Minnesota codes in the range 1-1-1 to $1-2-5$ plus 1-2-7).

\section{STATISTICAL METHODS}

Risk factors for coronary heart disease in cases and controls were examined using the unpaired $t$ test and $z$ test in the comparison of means and proportions. Homocysteine, vitamin B-12, alcohol, and triglycerides were not normally distributed and all calculations were done on log transformed (natural log) data; geometric means (antilog) are given in the tables. 
Table 1 Characteristics of study population and risk factors for coronary heart disease

\begin{tabular}{|c|c|c|c|}
\hline Means & Cases (mean (SD)) & $\begin{array}{l}\text { Controls (mean } \\
(S D))\end{array}$ & $p$ Value ( $t$ test) \\
\hline Age at phase II (years) & $58.1(4.3)$ & $58.1(4.3)$ & 0.8 \\
\hline \multicolumn{4}{|l|}{ Blood pressure } \\
\hline $\mathrm{SBP}(\mathrm{mm} \mathrm{Hg})$ & $154.2(25.3)$ & $146.4(22.3)$ & $<0.0001$ \\
\hline $\mathrm{DBP}(\mathrm{mm} \mathrm{Hg})$ & $87.4(14.5)$ & $84.5(11.9)$ & 0.0002 \\
\hline \multicolumn{4}{|l|}{ Blood lipids } \\
\hline Total cholesterol (mmol/l) & $6.9(1.1)$ & $5.6(1.0)$ & $<0.0001$ \\
\hline HDL cholesterol $(\mathrm{mmol} / \mathrm{l})$ & $0.9(0.2)$ & $1.0(0.2)$ & 0.0003 \\
\hline Triglycerides ${ }^{\star}(\mathrm{mmol} / \mathrm{l})$ & $1.9(1.6)$ & $1.7(1.5)$ & $<0.0001$ \\
\hline \multicolumn{4}{|l|}{ Clotting factors } \\
\hline Fibrinogen $(\mathrm{g} / \mathrm{l})$ & $4.2(0.94)$ & $4.0(0.9)$ & 0.001 \\
\hline \multicolumn{4}{|l|}{ Dietary factors } \\
\hline Folate ( $\mu \mathrm{g} /$ day $)$ & $271.5(82.1)$ & $278.3(75.9)$ & 0.2 \\
\hline Vitamin $\mathrm{B}-12^{\star}(\mu \mathrm{g} /$ day $)$ & $6.7(1.9)$ & $6.7(1.9)$ & 0.8 \\
\hline Vitamin B-6 (mg/day) & $1.1(0.5)$ & $1.2(0.5)$ & 0.002 \\
\hline Alcohol* (ml/day) & $40.0(6.7)$ & $58.8(5.5)$ & $<0.001$ \\
\hline $\mathrm{BMI}\left(\mathrm{kg} / \mathrm{m}^{2}\right)$ & $26.3(3.5)$ & $25.9(3.7)$ & 0.2 \\
\hline Creatinine $(\mu \mathrm{mol} / \mathrm{l})$ & $102.1(20.2)$ & $99.3(14.6)$ & 0.005 \\
\hline Percentages & $\%(S E)$ & $\%(S E)$ & $z$ test \\
\hline Diabetes & $5.8(1.3)$ & $3.4(0.5)$ & 0.05 \\
\hline Hypertension & $61.5(2.8)$ & $42.9(1.4)$ & $<0.0001$ \\
\hline Angina & $22.4(2.4)$ & $10.7(0.9)$ & $<0.0001$ \\
\hline ECG ischaemia & $29.8(2.6)$ & $14.6(0.9)$ & $<0.0001$ \\
\hline \multicolumn{4}{|l|}{ Smoking } \\
\hline Ever & $87.4(1.9)$ & $82.3(1.1)$ & 0.03 \\
\hline Ex- & $34.2(2.7)$ & $39.9(1.4)$ & 0.06 \\
\hline Current & $53.2(2.8)$ & $42.4(1.4)$ & $<0.001$ \\
\hline $1-14$ cigarettes/day & $20.3(2.3)$ & $16.1(1.0)$ & 0.09 \\
\hline 15-24 cigarettes/day & $13.5(1.9)$ & $11.9(0.9)$ & 0.4 \\
\hline$>25$ cigarettes/day & $8.7(1.6)$ & $6.2(0.7)$ & 0.2 \\
\hline Manual social class & $70.8(2.6)$ & $67.1(1.3)$ & 0.2 \\
\hline
\end{tabular}

${ }^{\star}$ Geometric mean.

BMI, body mass index; DBP, diastolic blood pressure; HDL, high density lipoprotein; SBP, systolic blood pressure. current smoking, cholesterol:high density lipoprotein (HDL) ratio, triglycerides, fibrinogen, prevalent coronary heart disease; then factors which are inversely associated with both homocysteine concentration and coronary heart disease but are possibly on the causal pathway, such as the $\mathrm{B}$ vitamins and alcohol (D); finally, we adjusted for variables that appear to be confounders though without a definite biological explanation, such as diabetes, body mass index, and creatinine (E).

\section{Results}

There were 312 coronary heart disease events: 273 incident events between phases II and IV, and 39 deaths reported up to April 1998. Of the 312 coronary heart disease cases, 172 men had a fatal coronary heart disease event and 140 had a non-fatal event. Of 1560 men in the analysis, 361 were dead from all causes by the end of the follow up period (194 cases and 167 controls). Among controls, homocysteine concentration was greater in the non-survivors $(12.5 \mu \mathrm{mol} / 1,95 \%$ CI 11.4 to $11.9 \mu \mathrm{mol} / \mathrm{l})$ than in the survivors $(11.7 \mu \mathrm{mol} / 1,95 \%$ CI 11.8 to $13.14 \mu \mathrm{mol} / \mathrm{l})$, and the difference was significant $(p=0.01)$. The mean age at phase II for both cases and controls was 58.1 years. Geometric mean homocysteine concentration of 68 men who reported that they were not fasting $(11.8 \mu \mathrm{mol}, 95 \%$ CI 10.9 to $12.7 \mu \mathrm{mol} / 1$; 16 cases and 52 controls) did not differ from those who were fasting $(11.9 \mu \mathrm{mol}, 95 \% \mathrm{CI}$ 11.6 to $12.0 \mu \mathrm{mol} / \mathrm{l})(\mathrm{p}=0.8)$. Geometric mean homocysteine concentration in cases (12.2 $\mu \mathrm{mol}, 95 \%$ CI 11.8 to $12.6 \mu \mathrm{mol} / \mathrm{l})$ was higher than in controls $(11.8 \mu \mathrm{mol}, 95 \% \mathrm{CI}$ 11.6 to $12.0 \mu \mathrm{mol} / \mathrm{l})$, but the difference was not significant $(p=0.09)$. Geometric mean homocysteine concentration in fatal coronary heart disease cases was $12.5 \mu \mathrm{mol} / 1$ (95\% CI 11.9 to $13.0 \mu \mathrm{mol} / \mathrm{l})$ and $11.9 \mu \mathrm{mol} / 1$ (95\% CI 11.3 to $12.5 \mu \mathrm{mol} / \mathrm{l})$ in non-fatal cases $(\mathrm{p}=0.2)$.

Table 1 show the characteristics of the study population according to risk factors for coronary heart disease. Cases had a significantly higher mean systolic and diastolic blood pressure, and higher serum triglycerides, total cholesterol, and fibrinogen than controls. Mean HDL cholesterol, daily alcohol consumption, and vitamin B-6 intake were lower in cases than in controls. Diabetes, hypertension, and current smoking were more common in cases than in controls.

Table 2 shows the relation between homocysteine concentration and potential confounding variables in the controls. The correlation coefficients correspond to the change in $\log$ transformed homocysteine concentration with every unit change in risk factor. Age had a strong positive relation to homocysteine concentration, as did smoking. Those with hypertension had higher mean homocysteine concentration, although the difference was not significant. There is a significant inverse relation between homocysteine concentration and the $\mathrm{B}$ vitamins, folate, B-12, and B-6. Alcohol and body mass index also showed an inverse relation, as did total cholesterol and HDL cholesterol. then non-coronary deaths (B); then traditional risk factors strongly associated with coronary heart disease (C), such as hypertension, 
Table 2 Serum total homocyst(e) ine and potential confounding variables for coronary heart disease in the control group

\begin{tabular}{|c|c|c|c|}
\hline & Linear regression & $95 \% C I$ & p Value \\
\hline & $\beta$ Coefficient $^{\star}$ & & \\
\hline Age (per 5 years) & 0.033 & 0.01 to 0.05 & 0.001 \\
\hline \multicolumn{4}{|l|}{ Blood pressure } \\
\hline Systolic BP (per $10 \mathrm{~mm} \mathrm{Hg}$ ) & 0.0046 & -0.003 to 0.01 & 0.2 \\
\hline Diastolic BP (per $10 \mathrm{~mm} \mathrm{Hg}$ ) & -0.0016 & -0.29 to 0.19 & 0.8 \\
\hline \multicolumn{4}{|l|}{ Dietary factors } \\
\hline †Alcohol (per SD, ml/d) & -0.044 & $\begin{array}{l}-0.062 \text { to } \\
-0.02\end{array}$ & $<0.001$ \\
\hline Folate (per SD, $\mu \mathrm{g} / \mathrm{d}$ ) & -0.056 & -0.07 to -0.03 & $<0.001$ \\
\hline +Vit B-12(per SD, $\mu \mathrm{g} / \mathrm{d})$ & -0.053 & -0.07 to -0.03 & $<0.001$ \\
\hline Vit B-6 (per SD, mg/d) & -0.035 & -0.05 to -0.01 & $<0.001$ \\
\hline \multicolumn{4}{|l|}{ Blood lipids } \\
\hline Total cholesterol (per SD, mmol/l) & -0.021 & $\begin{array}{l}-0.03 \text { to } \\
-0.004\end{array}$ & 0.01 \\
\hline HDL cholesterol (per SD, mmol/l) & -0.019 & $\begin{array}{l}-0.03 \text { to } \\
-0.002\end{array}$ & 0.02 \\
\hline †Triglycerides (per SD, mmol/l) & -0.010 & -0.05 to 0.01 & 0.03 \\
\hline \multicolumn{4}{|l|}{ Clotting factors } \\
\hline Fibrinogen $($ per SD, g/l) & -0.002 & -0.014 to 0.20 & 0.7 \\
\hline Body mass index $\left(10 \mathrm{~kg} / \mathrm{m}^{2}\right)$ & -0.10 & -0.15 to -0.06 & $<0.001$ \\
\hline \multirow[t]{2}{*}{ Creatinine (per SD, $\mu \mathrm{mol} / \mathrm{l}$ ) } & 0.06 & 0.04 to 0.08 & $<0.001$ \\
\hline & Serum tHcy $(\mu m / l)$ & $S D$ & \\
\hline \multicolumn{4}{|l|}{ Smoking } \\
\hline Never smoked & 11.3 & 1.3 & \\
\hline Ex-smoker & 11.7 & 1.4 & \\
\hline \multirow[t]{4}{*}{ Current smoker } & 12.1 & 1.4 & \\
\hline & & ANOVA, $\mathrm{p}=0.0$ & \\
\hline & Difference in means & & \\
\hline & $\begin{array}{l}\text { Serum tHcy }(\mu m / l) \\
(S D)\end{array}$ & \multicolumn{2}{|l|}{$t$ Test $p$ value } \\
\hline Hypertensive & $11.9(1.4)$ & \multirow{2}{*}{\multicolumn{2}{|c|}{0.2}} \\
\hline Normotensive & $11.7(1.4)$ & & \\
\hline Manual social class & $11.9(1.4)$ & \multirow{2}{*}{\multicolumn{2}{|c|}{0.2}} \\
\hline Non-manual social class & $11.6(1.4)$ & & \\
\hline Angina & $12.2(1.4)$ & \multirow{2}{*}{\multicolumn{2}{|c|}{0.2}} \\
\hline No angina & $11.7(1.4)$ & & \\
\hline ECG ischaemia & $11.9(1.3)$ & \multirow{2}{*}{\multicolumn{2}{|c|}{0.6}} \\
\hline Normal ECG & $11.8(1.4)$ & & \\
\hline
\end{tabular}

${ }^{\star}$ Change in homocysteine (natural log) per unit change in CHD risk factor.

†Log transformed.

ANOVA, analysis of variance; BP, blood pressure; HDL, high density lipoprotein; tHcy, total serum homocyst(e)ine concentration.

Table 3 Odds ratio of coronary heart disease, comparing each quintile in the total serum homocyst(e) ine ( $t H c y)$ concentration with the first

\begin{tabular}{lllll}
\hline $\begin{array}{l}\text { Quintile of } \\
\text { tHcy }\end{array}$ & $\begin{array}{l}\text { Age adjusted OR } \\
\text { (95\% CI) }\end{array}$ & p Value & $\begin{array}{l}\text { Adjusted }{ }^{\star} \text { OR } \\
\text { (95\% CI) }\end{array}$ & p Value \\
\hline 1 & 1 & & 1 & \\
2 & $1.33(0.8$ to 2.1$)$ & $\mathrm{p}=0.2$ & $1.32(0.8$ to 2.1$)$ & $\mathrm{p}=0.23$ \\
3 & $1.63(1.1$ to 2.5$)$ & $\mathrm{p}=0.02$ & $1.43(0.9$ to 2.2$)$ & $\mathrm{p}=0.11$ \\
4 & $1.43(0.93$ to 2.2$)$ & $\mathrm{p}=0.1$ & $1.27(0.8$ to 2.0$)$ & $\mathrm{p}=0.30$ \\
5 & $1.61(1.1$ to 2.5$)$ & $\mathrm{p}=0.03$ & $1.31(0.8$ to 2.1$)$ & $\mathrm{p}=0.25$ \\
$\mathrm{p}$ Trend & 0.04 & & 0.4 &
\end{tabular}

$\mathrm{n}=1453$

*Adjusted for age, smoking current, hypertension, total cholesterol:high density lipoprotein ratio, fibrinogen, triglycerides, prevalent coronary heart disease, non-coronary death, folate, vitamin B-12, vitamin B-6, alcohol, diabetes, body mass index, and creatinine.

Table 4 Odds ratio (OR) of coronary heart disease for one SD change in serum total homocyst(e)ine concentration concentration adjusted for confounding variables

\begin{tabular}{llllll}
\hline & $n$ & Crude OR (95\% CI) & \multicolumn{3}{c}{ Adjusted OR (95\% CI) } \\
\hline A & 1560 & $1.11(0.98$ to 1.25$)$ & $\mathrm{p}=0.09$ & $1.11(0.98$ to 1.25$)$ & $\mathrm{p}=0.09$ \\
$\mathrm{~B}$ & 1560 & $1.11(0.98$ to 1.23$)$ & $\mathrm{p}=0.90$ & $1.12(0.99$ to 1.27$)$ & $\mathrm{p}=0.06$ \\
$\mathrm{C}$ & 1529 & $1.12(0.99$ to 1.26$)$ & $\mathrm{p}=0.07$ & $1.09(0.95$ to 1.24$)$ & $\mathrm{p}=0.20$ \\
$\mathrm{D}$ & 1489 & $1.13(1.00$ to 1.28$)$ & $\mathrm{p}=0.05$ & $1.09(0.95$ to 1.25$)$ & $\mathrm{p}=0.21$ \\
$\mathrm{E}$ & 1453 & $1.14(1.00$ to 1.29$)$ & $\mathrm{p}=0.04$ & $1.07(0.93$ to 1.24$)$ & $\mathrm{p}=0.34$ \\
\hline
\end{tabular}

A, age; B, non-coronary deaths; C, above variable plus hypertension, current smoking, total cholesterol:high density lipoprotein ratio, fibrinogen, triglycerides, and prevalent coronary heart disease; $\mathrm{D}$, the above variables plus folate, vitamin $\mathrm{B}-12$, vitamin $\mathrm{B}-6$, alcohol, and non-coronary death; E, the above variables plus diabetes, body mass index, and creatinine.
Table 3 shows the crude and adjusted odds ratios of coronary heart disease, comparing each quintile of homocysteine concentration with the first. The change in crude odds ratio with increasing quintiles is significant when tested for trend, but the relation is attenuated when adjusted for confounding factors.

The development of the logistic regression model is illustrated in table 4 . The odds ratio of coronary heart disease per standard deviation increase in log transformed homocysteine concentration $(0.308$ or antilog $1.38 \mu \mathrm{mol} / \mathrm{l})$ of the control distribution is presented. Once again, a moderate effect is attenuated by inclusion of confounding variables. There was no difference in the results when prevalent coronary heart disease was included or excluded. There was no interaction between homocysteine concentration and age at phase II, and in stratified analysis there was no difference in the odds ratio of coronary heart disease per standard deviation change in homocysteine concentration in younger men $(<58$ years) compared with older men ( $>58$ years). Examining for threshold effects, the adjusted odds ratio of coronary heart disease comparing the top 20\% of the homocysteine concentration distribution with the rest was 1.03 (95\% CI 0.73 to 1.45 ) $(\mathrm{p}=0.8)$, and comparing the top 5\% with the rest it was 1.05 (95\% CI 0.56 to 1.95$)$ $(\mathrm{p}=0.9)$.

\section{Discussion}

There was a small but non-significant association between increasing homocysteine concentration and coronary heart disease. The crude odds ratio of coronary heart disease with every standard deviation change in log transformed homocysteine concentration is of borderline significance but this disappears when controlled for confounding variables. There was also a weak trend across quintiles of homocysteine concentration, but this again is attenuated after adjustment. This evidence is consistent with other prospective cohort studies which have failed to show an increased risk $^{11}{ }^{15-17}$ and is clearly different from those that have shown a positive association..$^{7-9} 1422$

There are several possible explanations for why the results of cohort studies of homocysteine concentration and coronary heart disease differ so much.

\section{STATISTICAL ISSUES}

The null studies may not have enough power to detect a small increase in risk. This is unlikely in our reanalysis, with 312 cases and four controls for each case. This is almost twice as many as in the previous analysis ${ }^{18}$ and larger than in most of the major population based positive studies. ${ }^{7-9}$ On the other hand the positive findings in some cohort studies may be a result of chance. This is especially likely in the US physicians study, ${ }^{10}$ which found a significant result at the $5 \%$ homocysteine concentration cut off but failed to reproduce this in three subsequent papers with longer follow up. ${ }^{11-13}$ 
MISCLASSIFICATION

Most prospective studies used stored blood samples to determine homocysteine concentration. If homocysteine concentrations were unstable over time this would result in non-differential or random misclassification and give a false negative result. However, there is evidence that homocysteine concentration is stable over $10^{23}$ and 14 years. ${ }^{17}$ Our samples were stored between $6-10$ years.

\section{CONFOUNDING}

In cohort studies of homocysteine concentration and coronary heart disease there is little or no consistency in the choice of confounding factors and how the multivariate model is presented. Misclassification of confounders and omitting to control for them may lead to false positive or false negative results. Raised homocysteine concentrations are associated with other coronary heart disease risk factors, particularly smoking and hypertension. ${ }^{4}$ One positive study ${ }^{8}$ did not control for smoking. In our analysis, current smoking and hypertension accounted for almost all of the association between homocysteine concentration and coronary heart disease, and adjusting for the other risk factors made very little difference. Adjustment was made for all possible confounding variables, but to avoid the possibility of overcontrolling for factors that are on the causal pathway, such as folate and vitamin B-12, models are presented both with and without these variables. An even greater problem is the control of variables such as diabetes, body mass index, and creatinine, where biological mechanisms are unclear. Adjusting for a large number of confounders could reduce the power of this study. However, the width of the confidence intervals is very similar before and after adjustment. Total serum homocysteine concentration has been associated with all cause mortality, ${ }^{24}$ and there was a significant difference in means among the controls between the survivors and nonsurvivors. The analysis was adjusted for non-coronary deaths but this did not change the overall results.

The $\mathrm{B}$ vitamins are potentially protective against coronary heart disease, and are inversely correlated with homocysteine concentration. There is an assumption in published reports that the $\mathrm{B}$ vitamins protect against coronary heart disease by lowering homocysteine concentration. ${ }^{2}$ However, if they have an independent protective effect, the positive association between homocysteine concentration and coronary heart disease may just be a proxy for vitamin B deficiency.

REVERSE CAUSALITY

There is evidence that homocysteine concentration increases after a vascular event. ${ }^{2526}$ Positive case-control ${ }^{27}$ and cross sectional studies $^{4}$ are possibly subject to reverse causation, where raised homocysteine concentration may be a result rather than the cause of coronary heart disease. However, this may also be a problem for cohort studies, where subclinical or asymptomatic coronary heart disease may be present in the population at recruitment; these participants are more likely to go on to become cases. In the recent British regional heart study, ${ }^{14}$ when men with pre-existing heart disease were excluded ( $44 \%$ of the cases $v 26 \%$ of controls), the odds ratio of a coronary heart disease event, comparing the top quintile of the homocysteine concentration distribution with the other four fifths, was reduced: 1.54 (95\% CI 1.01 to 2.34 ) v 1.75 (95\% CI 1.2 to 2.55 ). A history of angina pectoris and ischaemia on ECG were controlled for in this analysis. The analysis was repeated, excluding all those with prevalent disease at baseline, and the results did not change.

The US physicians study found a positive association between coronary heart disease and homocysteine concentration at their five year follow up, which was not reproducible at longer follow up. Studies that have a longer follow up tend to have null results. ${ }^{16}{ }^{17}$ Positive findings with a short term follow up could occur as a result of prevalent cardiovascular disease. Alternatively, homocysteine concentration could be a good short term predictor of disease but a poor long term predictor.

POPULATION HETEROGENEITY

There is some evidence that the mean homocysteine concentration varies between countries. ${ }^{28}$ Genuine systematic differences in the characteristics of the populations studied may account for the different estimates of effect in various studies. US physicians are likely to be a healthy group without vitamin deficiencies and without extreme homocysteine concentration values, and if homocysteine concentration was only toxic at very high levels the association may not be detectable. The Caerphilly cohort is a population of predominantly working class men, where a poorer diet is possible. With a high incidence of coronary heart disease and reliable measurement of a large number of confounding factors including dietary measures, it is ideally suited to testing the association between coronary heart disease and homocysteine concentration, if one exists. Wald and colleagues studied relatively young men, ${ }^{8}$ and other cohorts have detected a differential age effect of homocysteine concentration on coronary heart disease which is stronger in the younger group. ${ }^{70}$ It may be that homocysteine concentration is only associated with an increased risk in coronary heart disease at very high levels or in young men, and that the null findings in population based cohorts are real.

\section{STUDY HETEROGENEITY}

In the last two years, three reviews, ${ }^{1}{ }^{29} 30$ one systematic review, ${ }^{31}$ and one meta-analysis ${ }^{32}$ have been published on the association between homocysteine concentration and cardiovascular disease, identifying some common issues. Relative effect sizes become smaller and closer to the null when more rigorous epidemiological methods are employed. Also, combining results and calculating summary estimates of the relation between homocysteine concentration and coronary heart disease is not 
possible because of heterogeneity between studies - particularly the use of data derived cut off points, the study of diverse populations, and differing availability of confounding variables.

\section{CONCLUSION}

Our study does not support the hypothesis that homocysteine concentration is a strong independent risk factor for coronary heart disease. Public health policy makers must be wary of generalising early positive results, and initial excitement over homocysteine concentration has already been tempered by a more realistic appraisal of its importance. In the future, as well as more population based studies reporting their results, meta-analyses of all available individual participant data, as opposed to only published data, will provide a better quantitative summary estimate of the relation between homocysteine concentration and coronary heart disease. However, only randomised controlled trials of folic acid supplementation will provide evidence as to whether interventions that lower homocysteine concentration will prevent coronary heart disease.

Bristol is the lead centre of the MRC Health Services Research Collaboration. Una Fallon is a Wellcome Training Fellow in Clinical Epidemiology.

1 Refsum H, Ueland PM, Nygard O, et al. Homocysteine and cardiovascular disease. Ann Rev Med 1998;49:31-62.

2 Ward M, McNulty H, McPartlin J, et al. Plasma homocysteine, a risk factor for cardiovascular disease, is lowered cysteine, a risk factor for cardiovascular disease, is lowered
by physiological doses of folic acid. $O F M$ 1997;90:519-24.

3 McCully KS. Homocysteine and vascular disease. Nat Med McCully KS. Hom

4 Nygard O, Vollset SE, Refsum H, et al. Total plasma homocysteine and cardiovascular risk profile. The Hordaland homocysteine study. $\mathscr{F} A M A$ 1995;274:1526-33

5 Clarke R, Daly L, Robinson K, et al. Hyperhomocysteinemia: an independent risk factor for vascular disease. N Engl f Med 1991;324:1149-55.

6 Boushey CJ, Beresford SA, Omenn GS, et al. A quantitative assessment of plasma homocysteine as a risk factor for vascular disease. Probable benefits of increasing folic acid intakes. $\mathscr{F} A M A$ 1995;274:1049-57.

7 Arnesen E, Refsum H, Bonaa KH, et al. Serum total homocysteine and coronary heart disease. Int 7 Epidemiol 1995;24:704-9.

8 Wald NJ, Watt HC, Law MR, et al. Homocysteine and ischemic heart disease: results of a prospective study with implications regarding prevention. Arch Intern Med 1998; 158:862-7.

9 Bots ML, Launer LJ, Lindemans J, et al. Homocysteine and short term risk of myocardial infarction and stroke in the elderly - the Rotterdam study. Arch Intern Med 1999;159: $38-44$.

10 Stampfer MJ, Malinow MR, Willett WC, et al. A prospective study of plasma homocyst(e)ine and risk of myocardial infarction in US physicians. $\mathscr{F} A M A$ 1992;268:877-81.
11 Chasan-Taber L, Selhub J, Rosenberg IH, et al. A prospective study of folate and vitamin B6 and risk of myocardial infarcstudy of folate and vitamin B6 and risk of myocardial in
tion in US physicians. F Am Coll Nutr 1996;15:136-43.

12 Verhoef P, Hennekens CH, Malinow MR, et al. A prospective study of plasma homocyst(e)ine and risk of ischemic stroke. Stroke 1994;25:1924-30.

13 Verhoef P, Hennekens CH, Allen RH, et al. Plasma total homocysteine and risk of angina pectoris with subsequent coronary artery bypass surgery. Am f Cardiol 1997;79:799801.

14 Whincup PH, Refsum H, Perry IJ, et al. Serum total homocysteine and coronary heart disease: prospective study in middle aged men. Heart 1999;82:448-54.

15 Folsom AR, Nieto FJ, McGovern PG, et al. Prospective study of coronary heart disease incidence in relation to fasting total homocysteine, related genetic polymorphisms, and B vitamins: the Atherosclerosis Risk in Communities (ARIC) study. Circulation 1998;98:204-10.

16 Evans RW, Shaten BJ, Hempel JD, et al. Homocyst(e)ine and risk of cardiovascular disease in the Multiple Risk Fac-
tor Intervention Trial. Arterioscler Thromb Vasc Biol 1997;17:1947-53.

17 Alfthan G, Pekkanen J, Jauhiainen M, et al. Relation of serum homocysteine and lipoprotein(a) concentrations to atherosclerotic disease in a prospective Finnish population based study. Atherosclerosis 1994;106:9-19.

18 Ubbink JB, Fehily AM, Pickering J, et al. Homocysteine and ischaemic heart disease in the Caerphilly cohort. Atherosclerosis 1998;140:349-56.

19 Yarnell JW, Baker IA, Sweetnam PM, et al. Fibrinogen, viscosity, and white blood cell count are major risk factors for ischemic heart disease. The Caerphilly and Speedwell collaborative heart disease studies. Circulation 1991;83:836-

20 The Caerphilly and Speedwell Collaborative Group. Caerphilly and Speedwell collaborative heart disease studies. $\mathcal{F}$ Epidemiol Community Health 1984;38:259-62.

21 Ubbink JB, Hayward VW, Bissbort S. Rapid highperformance liquid chromatographic assay for total homocysteine levels in human serum. f Chromatogr 1991;565: $441-6$.

22 Bostom AG, Silbershatz H, Rosenberg IH, et al. Nonfasting plasma total homocysteine levels and all-cause and cardiovascular disease mortality in elderly Framingham men and women. Arch Intern Med 1999;159:1077-80.

23 Israelsson B, Brattstrom L, Refsum H. Homocysteine in frozen plasma samples. A short cut to establish hyperhomocysteinaemia as a risk factor for arteriosclerosis? Scand $\mathcal{F}$ Clin Lab Invest 1993;53:465-9.

24 Hoogeveen EK, Kostense PJ, Jakobs C, et al. Hyperhomocysteinemia increases risk of death, especially in type 2 diabetes: 5-year follow-up of the Hoorn Study. Circulation 2000;101:1506-11.

25 Lindgren A, Brattstrom L, Norrving B, et al. Plasma homocysteine in the acute and convalescent phases after stroke. cysteine in the acute and

26 Egerton W, Silberberg J, Crooks R, et al. Serial measures of plasma homocyst(e)ine after acute myocardial infarction. Am f Cardiol 1996;77:759-61

27 Graham IM, Daly LE, Refsum HM, et al. Plasma homocysteine as a risk factor for vascular disease. The European Concerted Action Project. FAMA 1997;277: 1775-81.

28 Alfthan G, Aro A, Gey KF. Plasma homocysteine and cardiovascular disease mortality. Lancet 1997;349:397.

29 Hankey GJ, Eikelboom JW. Homocysteine and vascular disease. Lancet 1999;354:407-13.

30 Eikelboom JW, Lonn E, Genest JJ, et al. Homocyst(e)ine and cardiovascular disease: a critical review of the and cardiovascular disease: a critical review of the

1 Christen WG, Ajani UA, Glynn RJ, et al. Blood levels of homocysteine and increased risks of cardiovascular disease: causal or casual? Arch Intern Med 2000;160:422-34.

32 Danesh J, Lewington S. Plasma homocysteine and coronary heart disease: systematic review of published epidemiological studies. F Cardiovasc Risk 1998;5:229-32. 